\title{
Chiari tip I malformasyonlu hastalarda korpus kallozumun morfometrik ölçümlerinin ve uzaysal oryantasyonunun değerlendirilmesi
}

\section{Evaluation of the morphometric measurement and spatial orientation of corpus callosum in patients with Chiari type I malformation}

\author{
Fuat Özkan*, Mehmet Fatih İnci, Betül Kızıldağ, Mehmet Sait Menzilcioğlu, \\ Mehmet Şenoğlu, Yakup Gümüşalan
}

Radyoloji Anabilim Dalı (Yrd. Doç. Dr. F. Özkan, Yrd. Doç. Dr. M. F. İnci), Beyin Cerrahisi Anabilim Dalı (Doç. Dr. M. Şenoğlu), Anatomi Anabilim Dalı (Prof. Dr. Y. Gümüşalan), Kahramanmaraş Sütçü İmam Üniversitesi Tıp Fakültesi, TR-46100 Kahramanmaraş, Radyoloji Anabilim Dalı (Yrd. Doç. Dr. B. Kızıldağ), Çanakkale Onsekiz Mart Üniversitesi Tıp Fakültesi, TR-17100 Çanakkale, Radyoloji Kliniği (Dr. M. S. Menzilcioğlu), Kahramanmaraş Necip Fazıl Şehir Hastanesi, TR-46100

\section{Özet}

Amaç. Bu çalışmada, Chiari tip I malformasyonlu hastalarda korpus kallozumun morfometrik ölçümleri ve birtakım açı ölçümleri ile tespit edilen uzaysal oryentasyonunu normal populasyona göre değerlendirmek amaçlanmıştır. Yöntem. 3-65 yaş arası 28 Chiari tip I malformasyonlu hasta (14 kadın, 14 erkek) ve 41 sağlıklı olgunun, T1 veya T2 ağırlıklı orta sagital kesitli MR görüntülerinde korpus kallozumun uzunluk, yükseklik, tepe açısı ve uzaysal oryentasyonunu belirleyen 4 farklı açı (A, B, C, D açıları) ölçümü yapıldı. Ölçümler arası farkı belirlemek için istatistiksel olarak Independent- $\mathrm{T}$ testi kullanıldı. Korelasyon için Pearson korelasyon testi kullanıldı. Bulgular. Her iki grup karşılaştırıldığında oryentasyon açılarından B ve D açılarında anlamlı bir fark olduğu bulundu $(\mathrm{p}<0,05)$. A ve $\mathrm{C}$ açılarında, korpus kallozumun uzunluk, yükseklik ve santral açı ölçümlerinde ise istatistiksel olarak anlamlı bir fark bulunmadı ( $>0,05)$.Yaş ile korpus kallozumun uzunluğu ve A açısı arasında pozitif korelasyon saptandı. (sırasıyla r: 0,446 p: 0,043, r: 0,494 p: 0,023). Cinsiyet ile morfometrik ölçümler ve açılar arasında anlamlı korelasyon saptanmadı. Sonuç. Korpus kallozumun uzaysal oryentasyonu Chiari tip I malformasyonlu olgularda normal populasyona göre farklılık göstermektedir. Bu sonuçlar, korpus kallozum çalışmalarında uzaysal oryentasyonun önemli bir faktör olabileceğini göstermekle birlikte daha geniş serilere ihtiyaç vardır.

Anahtar sözcükler: Chiari tip I malformasyonu, korpus kallozum, morfometrik ölçümler, uzaysal oryantasyon

\begin{abstract}
Aim. This study aimed to determine the morphometric measurement and spatial orientation of corpus callosum in patients with Chiari type I malformation. Methods. In 28 patients with Chiari type I malformation (14 women and 14 men) and 41 healthy individuals between the ages of 3-65, length and height of corpus callosum as well as the central angle and four angles (A, B, C, D angles) to understand the spatial characteristics of the callosum were measured in T1 or T2 weighted mid-sagittal MR images. Independent- $T$ test was used to determine the statistical differences between the measurements. Moreover Pearson's coefficient of correlation was used to determine the correlations. Results. B and D angles of corpus callosum compared between the groups, had a significant difference $(\mathrm{p}<0.001)$. There was no statistical difference between the length and height of corpus callosum, as well as the central angle and other two angles (A and C) for spatial characteristics of the corpus callosum $(p>0.05)$. There was a positive correlation between the age and length of corpus callosum and A angle (r: 0.446 p: 0.043, r: 0.494 p: 0.023, respectively). There was no correlation between gender and morphometric measurements. Conclusion. These results confirm that the spatial orientation of corpus callosum is different from the normal population in cases with Chiari Type I malformation. These results suggest that spatial orientation could be an important factor in studies of the corpus callosum, however, further studies are required with larger sample size.
\end{abstract}


Keywords: Chiari type I malformation, Corpus callosum, morphometric measurements, spatial orientation

Geliş tarihi/Received: 01 Ekim 2012; Kabul tarihi/Accepted: 12 Aralık 2012

\section{*İletişim adresi:}

Dr. Fuat Özkan, Radyoloji Anabilim Dalı, Kahramanmaraş Sütçü İmam Üniversitesi Tıp Fakültesi, TR-46100 Kahramanmaraş. E-posta: drfozkan@yahoo.com

\section{Giriş}

Chiari tip I Malformasyonu (CM) serebellar tonsillerin aşağı, spinal kanala doğru herniasyonu ile karakterizedir. En çok görülen tipi olup CM'nin bu şekli erişkin tipi olarak kabul edilir [1]. Anomali, baş ve ekstremite ağrıları, \%15-20'sinde alt kranial sinir tutulumuna bağlı olarak vokal kord paralizisi, vertigo, hipoestezi, ekstremitelerde güçsüzlük gibi silik ve değişik belirtiler gösterebilir [2]. Tanı bu nedenlerden dolayı genellikle zordur ve gecikmektedir. Korpus kallozum (KK), bir hemisfere ulaşan bilginin diğer hemisfere iletilmesinde rol oynayan en büyük ve en önemli yoldur. KK sağ ve sol beyin hemisferlerindeki ilgili merkezleri birbirine bağlar ve kalın miyelinli liflerden oluşur. Normal insanlarda KK'un birçok morfometrik ölçümü yapılmış olup hasta gruplarında ölçüm oldukça azdır [3-5]. Literatürde CM'nin KK'un komşu yapılar ile oluşturduğu birtakım açılar ile saptanan uzaysal oryentasyon üzerine etkisini araştıran bir çalışmaya rastlanılmamıştır.

Bu çalışmada amacımız CM'lu hastalarda KK'un morfometrik ölçümleri ve birtakım açı ölçümleri ile tespit edilen uzaysal oryentasyonunu normal populasyona göre değerlendirmektir.

\section{Gereç ve yöntem}

Bu çalışmaya 28 CM'lu hasta (14 kadın, 14 erkek) ve 41 (19 kadın, 22 erkek) sağlıklı birey alındı. Çalışmaya alınan CM'lu olguların yaş ortalaması 27 idi (3-65 yaş aralığı), kontrol grubunun ise 30 idi (3-65 yaş aralığı). Beyin cerrahisi polikliniğinde tedavi edilen CM'lu olguların manyetik rezonans görüntüleri (MRG) geriye dönük olarak incelendi. Operasyon geçiren hastalar çalışma dişı bırakıldı. Kontrol olguları ise dijital arşiv sisteminde (PACS) çeşitli nedenlerden dolayı istenmiş olan MRG görüntülerinde bir patolojiye rastlanmayan ve özgeçmişinde herhangi bir sorun olmayan hastalardan seçildi. MRG tetkikleri Philips Intera 1,5 T cihazı (Philips Medical Systems, Amsterdam, The Netherlands) kullanılarak yapıldı. T1 ağırlıklı görüntülemede kullanılan parametreler şu şekildeydi: TR/TE: 500/15, FOV:23, matriks 256 x 256, kalınlık 5 mm, aralık 1 mm, NEX 2-3. T2 ağırlıklı görüntülemede kullanılan parametreler şu şekildeydi: FOV 230 mm, matriks 256 x 256, kalınlık 5 mm, aralık 1 mm, NEX 2-3, TR/TE:7450/102. Ölçümler için orta sagital düzlemde KK'un en iyi görüntülendiği T1-T2 ağırlıklı kesitler seçildi. Görüntüler daha sonra Medical Image Processing, Analysis, and Visualization (MIPAV) isimli bilgisayar programına aktarılıp KK uzunluğu, yüksekliği, tepe açısı ve uzaysal oryentasyonunu belirleyen 4 farklı açı (A, B, C, D açıları) ölçüldü. Morfometrik ölçümler için; splenium ve genu alt kenarından geçen yatay bir çizgi ile KK uzunluğu ve bu horizontal çizgiye KK'un en yüksek noktasından çizilen dikey bir çizgi ile KK yüksekliği ölçüldü. Bu ölçümler ile KK hayali bir dikdörtgen içine alınmış olup, dikdörtgenin alt köşelerinden KK'un tepe noktasına çizilen iki çizgi ile tepe açısı ölçüldü (Resim 1). 


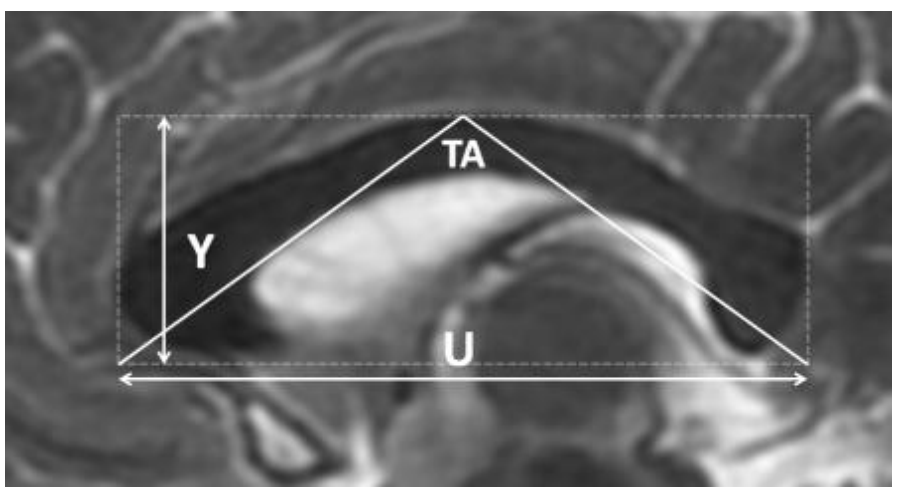

Resim 1. Korpus kallozumun morfometrik ölçümlerini gösteren midsagittal T2 ağırlıklı manyetik rezonans görüntüsü. Korpus kallozum yüksekliği (Y), uzunluğu (U) ve tepe açısı (TA) şekilde gösterildiği gibi ölçülmüştür.

KK'un uzaysal oryentasyonunu anlamak için Hwang ve ark. [6]'nın kullandığg 4 farklı (A, B, C, D) açı ölçüldü. Pons'un üst tarafındaki çentik analiz noktası olarak kullanıldı. Resim 2'de gösterilen 4 çizgi çizilerek ölçüm yapıldı. Bunlar; 1.çizgi, KK'un genu ve splenium'un alt kenarlarını birleştiren yatay olan çizgi, 2.çizgi; genu alt kenarı ile analiz noktasını birleştiren çizgi, 3.çizgi; splenium'un alt kenarı ile analiz noktasını birleştiren çizgi ve 4.çizgi; beyin sapı dorsalinden çizilen dikey bir çizgi idi. A açısı, pons'un üst tarafındaki çentikte 2. ve 3.çizgi arasındaki açı; B açısı, 1 ile 4. çizgi arasındaki üst anteriordaki açı; C açısı, 1 ile 3.çizgi arasındaki alt anteriordaki açı ve D açısı ise 2 . ve 4 . çizgi arasındaki üst anterior yerleşimli açıdır. Bu çizim ve ölçümler aynı araştırmacı tarafindan yapıldı. Bütün verilere SPSS 16.0 programında Independent Samples T testi, korelasyon için Pearson korelasyon testi uygulandı ve $\mathrm{p}<0,05$ olan sonuçlar anlamlı olarak kabul edildi.

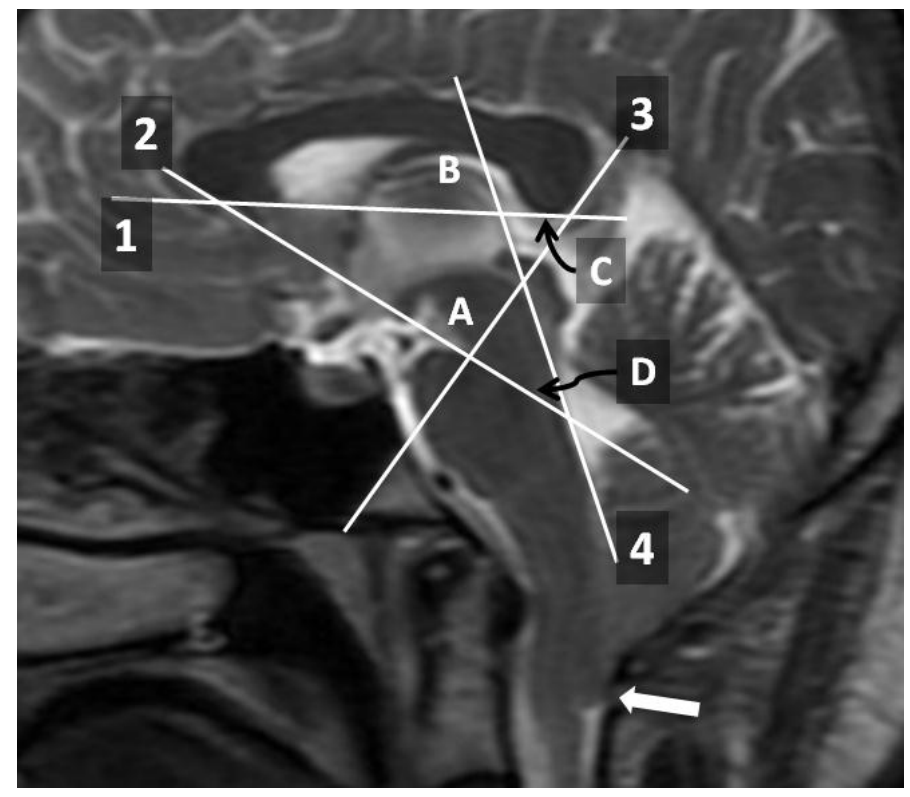

Resim 2. Korpus kallozum uzaysal oryentasyonunu belirleyen 4 farklı açıların (A, B, C, D açıları) ölçümünü gösteren midsagittal T2 ağırlıklı manyetik rezonans görüntüsü. Pons'un üst tarafındaki çentik analiz noktası olarak kullanıldı. Açılar 4 çizgi çizilerek elde edildi. Bunlar; 1.çizgi, KK'un genu ve splenium'un alt kenarlarını birleştiren yatay olan çizgi, 2.çizgi; genu alt kenarı ile analiz noktasını birleştiren çizgi, 3.çizgi; splenium'un alt kenarı ile analiz noktasını birleştiren çizgi ve 4.çizgi; beyin sapı dorsalinden çizilen dikey bir çizgisi. A açısı, pons'un üst tarafındaki çentikte 2. ve 3.çizgi arasındaki açı; B açısı, 1 ile 4 . çizgi arasındaki üst anteriordaki açı; $C$ açısı, 1 ile 3.çizgi arasındaki alt anteriordaki açı ve $D$ açısı ise 2. ve 4. çizgi arasındaki üst anterior yerleşimli açıdır. Serebellar tonsiller foramen magnumdan inferiora doğru elonge olarak izlenmektedir (beyaz ok). 


\section{Bulgular}

Hasta ve kontrol grubunun morfometrik ve açı değerleri Tablo 1'de verildi. B açısı CM'lu grupta ortalama değeri $76,07 \pm 5,56$ derece olup kontrol gurubuna $(79,4 \pm 5,75$ derece) göre anlamlı olarak düşüktü $(\mathrm{p}=0,03)$. Benzer şekilde $\mathrm{D}$ açısı $\mathrm{CM}^{\prime}$ 'lu grupta ortalama değeri $47,4 \pm 6,71$ derece olup kontrol gurubuna $(50,3 \pm 4,95$ derece) göre düşüktü $(\mathrm{p}=0,048)$. A ve C açıları, KK'un uzunluk, yükseklik, tepe açı ölçümlerinde ise istatistiksel olarak anlamlı bir fark bulunmadı $(p>0,05)$. Yaş ile KK uzunluğu ve A açısı arasında pozitif korelasyon saptandı (sırasıyla r: 0,446 p: 0,043, r: 0,494 p: 0,023). Cinsiyet ile morfometrik ölçümler ve açılar arasında anlamlı korelasyon saptanmadı.

Tablo 1. Grupların morfometrik ve açı değerlerinin karşılaştırılması.

\begin{tabular}{llll}
\hline Bölge & CM & Kontrol & p \\
\hline Uzunluk (mm) & $63,6 \pm 5,04$ & $66,2 \pm 4,77$ & 0,046 \\
Yükseklik (mm) & $24,4 \pm 3,21$ & $24,7 \pm 3,03$ & 0,746 \\
A (0) & $104,5 \pm 7,11$ & $103,5 \pm 6,61$ & 0,603 \\
B (0) & $76,07 \pm 5,56$ & $79,4 \pm 5,75$ & 0,03 \\
C (0) & $46,7 \pm 6,03$ & $48,2 \pm 5,91$ & 0,334 \\
D (0) & $47,4 \pm 6,71$ & $50,3 \pm 4,95$ & 0,048 \\
TA (0) & $106,7 \pm 7,86$ & $104,4 \pm 6,95$ & 0,247 \\
\hline CM: Chiari tip I malformasyon, TA: Tepe aç1S1
\end{tabular}

\section{Tartışma}

KK iki serebral hemisferdeki kortikal ve subkortikal nöronları fonksiyonel ve anatomik olarak birbirine bağlayan en büyük komissüral lif demetidir. Anterior komissürden başlayarak posterior bölümleri sırasıyla genu, trunkus ve splenium'dur. KK ve anterior komissür, memeli beyninde direkt olarak iki hemisferin neokorteksini bağlamak suretiyle algılama, kavrama, öğrenme ve istemli motor hareketlerin koordinasyonunu sağlamaktadır [3].

KK'un morfolojisini etkileyen pek çok faktör mevcuttur [4]. Bunların başında gelişimsel anomaliler, miyelinizasyondaki bozukluklar ve aksonların dejeneratif, iskemik veya travmatik nedenlerle kaybı yer alır [7, 8]. Diğer nedenler arasında cinsiyet [9-13], yaş [14, 15], sağ veya sol eli kullanma eğilimi [11] gibi demografik farklılıkların yanında, şizofreni [16] ve alkolizm [5] gibi hastalıklar sayılabilir.

KK'un kadın-erkek bireyler arasındaki morfometrik ölçüm farklarını göstermek için ilk çalışmalar De Lacoste ve ark. [9] tarafından yapılmış ve erişkin bayanlarda splenium daha büyük bulunmuştur. Kadın-erkek bireylerin KK'larının alan, görünüm ve uzunlukları ile ilgili ölçümlerde anlamlı farklılıklar gösteren çalışmalar olmasına rağmen [9, 13] hiçbir farklılığın olmadığını bildiren makaleler de mevcuttur [17, 18]. Halen literatürde kadın-erkek bireylerin KK'un morfometrik ölçüm değerleri ile ilgili olarak tam bir fikir birliği yoktur. Benzer bir şekilde cinsiyetin KK'un uzaysal oryentasyonu üzerine etkisini araştıran çalışmalarda da farklı sonuçlar elde edilmiştir. Hwang ve ark. [10]'nın yaptıkları bir çalışmada A, B, D açılarının kadınlarda, C açısının da erkeklerde geniş olduğu bulunmuştur [6]. Oka ve ark. [19] ise A ve C açılarının erkeklerde, B ve D açılarının ise kadınlarda geniş olduğunu belirtmişlerdir. Her iki çalışma da normal bireylerde yapıldığından bizim çalışmamızda cinsiyet karşılaştırması her iki grupta ayrı olarak yapılmıştır. Çalışmamızda CM'lu hastalarda her iki cinste açılar arasında anlamlı bir farklılık saptanmamışken, sağlıklı bireylerde $\mathrm{C}$ açısı erkeklerde anlamlı bir şekilde geniş bulunmuştur. Bu sonuç Hwang ve ark. [10]'nın yaptıkları çalışma ile uyumlu olmasına rağmen daha geniş serilere ihtiyaç vardır.

Cinsiyetin olduğu kadar yaşlanmanın da KK morfolojisi üzerine etkisi tartışmalıdır. Witelson ve ark. [11] yaşlanmaya bağlı KK alanının azaldığını, diğer çalışmalar ise bu alan azalmasına uzunluktaki azalmanın sebep olduğunu belirtmişlerdir [12, 13]. Diğer taraftan yaş ile KK uzunluğunun arttığını belirten yayınlar da mevcuttur $[14,15]$. Üstelik 
Takeda ve ark. [20] uzunluk artışına ek olarak yükseklik artışı da gözlemlemişlerdir. Bizim çalışmamızda yaş ile KK uzunluğu ve A açısı arasında pozitif korelasyon saptanmasına rağmen daha geniş serilere ihtiyaç vardır.

KK'un uzaysal oryentasyonu, KK'un komşu beyin yapıları ile arasındaki ilişkiyi gösteren göreceli bir parametredir [6]. Bununla birlikte bireysel farkl1lıklar ölçümleri etkileyebildiğinden dolayı Oka ve ark. [19] uzaysal oryentasyon için birçok açı ölçümü yapmıştır. Hwang ve ark. [6] bir çalışmalarında bu açıları hafif modifiye etmiş olup bizim çalışmamızda bu modifiye edilmiş açılar kullanılmıştır. B ve D açıları CM'lu grupta kontrol grubuna göre istatistiki olarak anlamlı bir şekilde düşük çıkmıştır. CM'lu hastalardaki düşük posterior fossa hacmi düşünüldügünde 1. ve 2. çizgi posteriora doğru yer değiştirecektir. Buna bağlı olarak B ve D açıları bizim çalışmamızda olduğu gibi daralacaktır. Birçok çalışmada CM'lu hastalardaki posterior fossa ve serebellar hacim değerleri sağlıklı bireyler ile karşılaştırıldığında düşük olarak bulunmuştur. Ancak bulunan değerler literatürde oldukça farklıdır. Furtado ve ark. [21] CM'lu hastalar ile yaş ve cinsiyet uyumlu sağlıklı bireyleri karşılaştırdıklarında posterior fossa hacminde yaklaşı $50 \mathrm{~cm}^{3}$ lük bir fark tespit etmişlerdir. Fakat Vurdem ve ark. [22]'nın yaptıkları bir çalışmada bu fark ortalama $19 \mathrm{~cm}^{3}$ iken, Nishikawa ve ark. [23]'nın yaptıkları çalışmalarda bu fark $7 \mathrm{~cm}^{3}$ 'e kadar düşmüştür. Bu hacim ölçümlerindeki farklılık değişik ölçüm metodlarının kullanılmasından ve hasta standardizasyonunun sağlanamamasından kaynaklanabilir.

Sonuç olarak; KK'un uzaysal oryentasyonu CM'li olgularda normal populasyona göre farklılık göstermektedir. Bu sonuçlar, KK çalışmalarında uzaysal oryentasyonun önemli bir faktör olabileceğini göstermekle birlikte daha geniş serilere ihtiyaç vardır.

\section{Kaynaklar}

1. Bejjani GK. Definition of the adult Chiari malformation: a brief historical overview. Neurosurg Focus 200; 11: E1.

2. Deniz FE, Öksüz E. Spontaneous syringomyelia resolution at an adult Chiari type 1 malformation. Turk Neurosurg 2009; 19: 96-8.

3. Eser O, Haktanır A, Boyacı MG, Doğan FA, Karavelioğlu E. Korpus kallozumun morfometrik ölçümleri. Türk Nöroşirürji Dergisi 2011; 21: 14-7.

4. Erdoğan N, Ulger H, Tuna I, Okur A. A novel index to estimate the corpus callosum morphometry in adults: callosal/supratentorial-supracallosal area ratio. Diagn Interv Radiol 2005; 11: 179-81.

5. Venkatasubramanian G, Anthony G, Reddy US, Reddy VV, Jayakumar PN, Benegal V. Corpus callosum abnormalities associated with greater externalizing behaviors in subjects at high risk for alcohol dependence. Psychiatry Res 2007; 156: 209-15.

6. Hwang SJ, Park C, Hong HN, Ryu JY, Rhyu IJ, Park IS. Effects of age and gender on spatial orientation of human corpus callosum in healthy Koreans. Animal Cells and Systems 2011; 15: 274-8.

7. Uchino A, Kato A, Yuzuriha T, Takashima Y, Kudo S. Cranial MR imaging of sequelae of prefrontal lobotomy. AJNR Am J Neuroradiol 2001; 22: 301-4.

8. Meguro K, Constans JM, Courtheoux P, Theron J, Viader F, Yamadori A. Atrophy of the corpus callosum correlates with white matter lesions in patients with cerebral ischaemia. Neuroradiology 2000; 42: 413-9.

9. DeLacoste-Utamsing C, Holloway RL. Sexual dimorphism in the human corpus callosum. Science 1982; 216: 1431-2.

10. Hwang SJ, Ji EK, Lee EK, Kim YM, Shin DY, Cheon YH, Rhyu IJ. Gender differences in the corpus callosum of neonates. Neuroreport 2004; 15: 1029-32.

11. Witelson SF. Hand and sex differences in the isthmus and genu of the human corpus callosum. A postmortem morphological study. Brain 1989; 112:799-835.

12. Byne W, Bleier R, Houston L. Variations in human corpus callosum do not predict gender: a study using magnetic resonance imaging. Behav Neurosci 1988; 
102: 222-7.

13. Allen LS, Richey MF, Chai YM, Gorski RA. Sex differences in the corpus callosum of the living human being. J Neurosci 1991; 11: 933-42.

14. Sullivan EV, Pfefferbaum A, Adalsteinsson E, Swan GE, Carmelli D. Differential rates of regional brain change in callosal and ventricular size: a 4-year longitudinal MRI study of elderly men. Cereb Cortex 2002; 12: 438-45.

15. Suganthy J, Raghuram L, Antonisamy B, Vettivel S, Madhavi C, Koshi R. Gender- and age-related differences in the morphology of the corpus callosum. Clin Anat 2003; 16: 396-403.

16. Serpa MH, Schaufelberger MS, Rosa PG, Duran FL, Santos LC, Muray RM, Scazufca M, Menezes PR, Busatto GF. Corpus callosum volumes in recent-onset schizophrenia are correlated to positive symptom severity after 1 year of followup. Schizophr Res 2012; 137: 258-9.

17. Luders E, Rex DE, Narr KL, Woods RP, Jancke L, Thompson PM, Mazziotta JC, Toga AW. Relationships between sulcal asymmetries and corpus callosum size: Gender and handedness effects. Cereb Cortex 2003; 13: 1084-93.

18. Bishop KM, Wahlsten D. Sex differences in the human corpus callosum: myth or reality? Neurosci Biobehav Rev 1997; 21: 581-601.

19. Oka S, Miyamoto O, Janjua NA, Honjo-Fujiwara N, Ohkawa M, Nagao S, Kondo $\mathrm{H}$, Minami T, Toyoshima T, Itano T. Re-evaluation of sexual dimorphism in human corpus callosum. Neuroreport 1999; 10: 937-40.

20. Takeda S, Hirashima Y, Ikeda H, Yamamoto H, Sugino M, Endo S. Determination of indices of the corpus callosum associated with normal aging in Japanese individuals. Neuroradiology 2003; 45: 513-8.

21. Furtado SV, Reddy K, Hegde AS. Posterior fossa morphometry in symptomatic pediatric and adult Chiari I malformation. J Clin Neurosci 2009; 16: 1449-54.

22. Vurdem ÜE, Acer N, Ertekin T, Savranlar A, Inci MF. Analysis of the volumes of the posterior cranial fossa, cerebellum, and herniated tonsils using the stereological methods in patients with Chiari type I malformation. ScientificWorldJournal 2012; 2012: 616934.

23. Nishikawa M, Sakamoto H, Hakuba A, Nakanishi N, Inoue Y. hdshdd Pathogenesis of Chiari malformation: a morphometric study of the posterior cranial fossa. J Neurosurg 1997; 86: 40-7. 